Collusion in Procurement Auctions: An Experimental Examination*

Douglas D. Davis

and

Bart J. Wilson*

RRH: DAVIS \& WILSON: COLLUSION IN PROCUREMENT AUCTIONS 


\title{
Collusion in Procurement Auctions: An Experimental Examination
}

\begin{abstract}
Experimental methods are used to examine the existence and detectability of collusion in environments that exhibit critical parallels to procurement auctions. We find that, given the opportunity, sellers often raise prices considerably. Moreover, non-collusive Nash equilibrium predictions are insufficient to dismiss "suspicious" behavior as innocuous: In an environment where identical prices are predicted in a non-collusive Nash equilibrium, common prices are observed only when sellers communicate. In a second environment designed to parallel construction procurement contracting, market rotations are observed both with and without collusion, but collusion can often be detected from the pattern of losing bids.
\end{abstract}




\section{INTRODUCTION}

Questioning the value of efforts to enforce Federal anti-conspiracy laws raises spirited debate among antitrust economists. Although everyone recognizes the welfare costs of successful conspiracies, commentators such as Armentano (1990) and Cohen and Scheffman (1989) argue that conspiratorial arrangements are pervasively ineffective, and thus, that social resources spent prosecuting collusion are wasted. Others, including Marvel, Netter and Robinson (1988) express more ambivalence about the seriousness of conspiracies as a social problem, but believe that the government manages to detect only the most ineffective arrangements. Still other economists clearly believe in the effectiveness of current government efforts (see e.g., Werden, 1989, and Froeb, Koyak and Werden, 1993).

Ultimately, the pervasiveness of conspiratorial behavior and the magnitude of the consequent damages are empirical issues. However, the illegality of collusion complicates the collection of relevant data. Tip-off's or complaints frequently expose conspiracies, but good reasons exist for suspecting that conspiracies detected in this fashion tend to be the least profitable. A conspirator likely "rats" on co-conspirators only if he or she is disenchanted with the scheme, suggesting that the conspiracy is about to collapse anyway. Similarly suspect are conspiracies that are sufficiently clumsy to raise the protests of buyers.

The detection problem would be vastly simplified if conspiracies could be identified in the absence of a "smoking gun." Posner (1969) argues that such explicit evidence of conspiratorial behavior is unnecessary, because conspiring firms exhibit identifiable patterns of activity that are alone sufficient to determine illegality. Kuhlman (1969) and Gallo (1977) go still further, and advocate the continuous computerized monitoring of pricing and sales data to detect conspiracies.

However, as Marshall and Muerer (1998) observe, a potentially condemning defect of any attempt to detect collusion via behavior is that, depending on underlying conditions, virtually any "suspect" pattern of behavior can be generated as a non-collusive Nash equilibrium. Identical 
prices, for example, are often cited as an indication of coordinated activity (e.g., Mund, 1960). ${ }^{1}$ But in games such as the one modeled by Anton and Yao (1992), agents submit identical bids in a Nash equilibrium, in the absence of collusion. Further, some evidence from collusion cases prosecuted by the Department of Justice suggests that identical prices are rarely part of collusive arrangements, except when the industry is not very concentrated (Comanor and Schankerman, 1976).

Market rotations, a second pricing scheme that is typically cited as a "suspect" pattern, may also be consistent with a subgame perfect non-cooperative Nash equilibrium. Zona (1986) for example, identifies a number of approximate equilibria involving contract rotations when sellers have steeply increasing cost structures. Also, Lang and Rosenthal (1991) characterize a noncooperative static equilibrium for a multi-product contracting environment, where sellers both divide the market and submit non-competitively high bids in the market where they do not expect to win. $^{2}$

Still other pricing patterns are possibly suspect. Porter and Zona (1993) report evidence of bid rigging in procurement auctions from the pattern of losing bids. The intuition is that in a competitive environment, bids should be correlated with costs. When prices are fixed, however, this correlation breaks down. ${ }^{3}$

This paper reports a laboratory experiment designed to explore the relationship between "suspect" behavior and collusion. We focus on coordinated behavior in procurement auctions, a context where collusion is often suspected, and has been frequently observed. ${ }^{4}$ Two environments are examined: A set cost regime that contains some features critical to standard government procurement auctions for goods, and an endogenous cost regime, which exhibits some critical elements of procurement bidding for construction contracts.

Of course, we cannot hope in simple and short-lived laboratory markets to replicate fully the circumstances under which natural conspiracies arise and persist. But the control offered by a 
laboratory experiment confers huge benefits. As the experimenter, we can specify precisely the underlying cost conditions, purchasing rules, and the opportunities to formulate conspiratorial agreements. ${ }^{5}$ Contingent upon these variables we can observe directly both instances where suspect patterns arise absent conspiracies, and, given cooperation, the type of conspiratorial arrangements formed.

Previous experimental research on price fixing suggests that the institutional context in which trading occurs can prominently affect conspiratorial behavior. In double-auction markets, which characterize trading in many financial exchanges, Isaac and Plott (1981) report that sellers are generally unable to raise prices when given an explicit opportunity to talk among themselves. However, explicit conspiracies are much more successful in retail-type posted-price markets (Isaac, Ramey, and Williams, 1984 and Siajo, Une, and Yamaguchi, 1996) and in sealed bid auctions (Isaac and Walker, 1985).

Even within the context of a particular trading institution, institutional and environmental details are important. Davis and Holt (1998) observe that opportunities to grant secret discounts from a posted price severely hamper conspiratorial efforts. In contrast to nearly uniform pricing at the joint profit-maximizing outcome in a series of baseline conspiracies, prices hovered about the competitive prediction when sellers were given the capacity to grant secret discounts from the posted-prices.

The remainder of this paper is organized as follows. Section II develops a pair of stylized bidding models where suspect patterns can be consistent with equilibrium bidding absent conspiracies. Section III presents the experimental design and procedures, and the results are discussed in Section IV. Section V offers some concluding remarks. 


\section{SUSPECT BEHAVIOR IN NON-COLLUSIVE MARKETS}

In this section we consider a pair of cost regimes where "suspicious" bid patterns can arise as equilibrium predictions in non-collusive environments. We begin with a set cost regime, where identical prices and an equal division of the market can arise without collusive bid-coordination. Then we develop an endogenous cost regime, where quantity rotations can be consistent with noncollusive equilibrium bidding. The section concludes by considering how efficiency and monitorability considerations might affect the collusive bid patterns selected in each of these regimes.

\section{$\underline{\text { A Set Cost Regime }}$}

Consider a stylized model of a standard multi-unit procurement auction. A single purchaser inelastically demands a fixed number of units of a good. Sellers provide units under condition of increasing marginal costs. For simplicity, assume that sellers' cost schedules are identical. The supply and demand configuration in Figure 1 illustrates. Here four sellers bid to sell four units to a single buyer. The seller identifiers, $S 1, S 2, S 3$ and $S 4$, printed below the cost steps on the market supply schedule, indicate the unit cost allocations for the four sellers. Each seller is endowed with four units with ascending costs $c_{a}, c_{b}, c_{c}$, and $c_{d}$. The buyer's allocation consists of four units, each valued at $r$ or more. ${ }^{6} \quad$ The action space for a seller $i$ is a two-dimensional bid, $B_{i}=\left(p_{i}, \hat{q}_{i}\right)$, consisting of a single price selected on a continuous grid, $p_{i} \in[0, \infty)$, and a discrete maximum quantity offer, $\hat{q}_{i} \in\{0,1,2,3,4\}$. At a bid price $p_{i}, c_{d}<p_{i}<r$, each seller can profitably clear the market. For the purposes of establishing the equilibria of this game, assume that the costs of each seller and the demand function are common knowledge. (We will discuss this assumption further in section III on the experimental procedures.) Finally, assume initially that in the event of a tie among the lowest bidders, the buyer uses a "rotating purchase rule," buying in turn single units from each 
of the tied sellers until either demand or the capacity supplied is exhausted. McAfee and McMillan (1992) report that State government purchasing agents typically use a purchasing rule of this type in procurement auctions.

Establishing that an identical price $P_{c}$ and market share are consistent with an equilibrium is straightforward. Suppose that the aggregate offer quantity is $\hat{Q}=\sum \hat{q}_{i}=6$, which implies that at least two sellers offer zero profit units. The buyer then purchases one unit from each seller, so for each seller, sales quantity $q_{i}=1$ and earnings are $c_{b}-c_{a}$. Any unilateral price decrease below $P_{c}$ will reduce earnings on a certain to sell unit. Any unilateral price increase will reduce earnings to zero.

In fact, given a continuous bid grid, all stage-game equilibria for this game involve the price $P_{c}$, as is easily verified via the standard arguments. Thus, to the extent that static Nash predictions organize behavior in this context, we should expect to observe "suspect" identical prices in this noncooperative environment. The sizable excess supply at the competitive price provides a fairly strong basis for viewing this design as a good candidate environment for generating identical prices.

Nevertheless, two features of this design might mitigate against identical prices. First, notice that all Nash equilibria in this design involve strategies with payoffs such that one player has another strategy that could yield an identical payoff. More specifically, in order to make unilateral defection unprofitable, some sellers must offer some units at zero profit. Sellers are necessarily indifferent between offering and not offering these units. If no zero-profit units are offered, deviation from $P_{c}$ becomes profitable, and the Nash equilibrium is broken. A Nash equilibrium with such strategies is an inherent deficiency of many simple procurement auction environment, since by assumption the buyer inelastically demands a limited number of units. ${ }^{7}$

Second, in virtually any natural context, an effective minimum bid increment exists. However, imposing a minimum bid increment creates additional pure-strategy equilibria near $P_{c}$. For specificity, restrict the bid grid to penny increments. Then, via the same reasoning used to 
establish the existence of an equilibrium at price $P_{c}$, equilibria at prices $P_{c}+1$ and $P_{c}+2$ can be shown to exist. ${ }^{8}$ Thus, equilibrium selection problems may prompt some continuing price heterogeneity in such contexts.

Selection problems aside, notice the sensitivity of equilibria in this design to the buyer's rule for breaking ties. Suppose that instead of using a rotating purchase tiebreaker, the buyer randomly selects one of the low-bidding sellers and makes as many purchases as possible. The buyer switches to a second seller only in the event that the first seller does not exhaust the buyer's demand. McAfee and McMillian (1992) report that government contracting agencies often switch to a "fixed purchase rule" of this type when collusion is suspected. This change in the purchasing rule breaks the pure strategy equilibrium at the common price $P_{c}$, since some zero profit units will sell in expectation, and any seller can increase expected earnings by posting $P_{c}-\varepsilon{ }^{9}$

\section{An Endogenous Cost Regime}

Bid rotations are a second pattern that can arise in a non-cooperative procurement context, if sellers face temporally sensitive capacity constraints of the type that might arise, for example, in the construction trades. When small contractors win a contract, they become essentially occupied, and take on further business only if the margins on the extra work are sufficiently high (see, e.g,. Zona, 1986 or Lang and Rosenthal, 1991). Consider the series of supply and demand arrays shown in the four panels of Figure 2. Initially, in period 1 shown in the upper left panel, all sellers have identical costs, $c_{a}$, and an aggregate supply of four units each. As before, each seller $i$ bids in a twodimensional action space $B_{i}=\left(p_{i}, \hat{q}_{i}\right)$, with continuous $p_{i} \in[0, \infty)$ and discrete $\hat{q}_{i} \in\{0,1,2,3,4\}$. The buyer has a minimum reservation value of $r$ per unit). Assume initially that sellers offer all units possible (e.g., $\hat{q}_{i}=4$ ), and that in the case of a tie, the buyer uses a fixed purchase tiebreaker. Without loss of generality, assume that $S 1$ is the winner in period 1 . Given a contract, $S 1$ faces a 
capacity constraint for the next three periods. The constraint binds most sharply in period 2, which is illustrated in panel 2, where $S 1$ 's costs increase to $c_{d}$. In subsequent periods the constraint becomes progressively less onerous, with seller $S 1$ 's costs falling to $c_{c}$ in period 3 , and to $c_{b}$ in period 4. S1 would again be the low cost bidder in period 5. The game is repeated indefinitely, with a discount factor of $\delta$. To distinguish this market from the structure just discussed above, we term it an "endogenous cost" design. ${ }^{10}$

A variety of outcomes can arise in this game, depending the cost realizations that evolve. These outcomes can be readily understood by considering stage game incentives for an iteration of the game after several rounds of bidding, when units on each cost step have been assigned. The most interesting (and perhaps the most likely) case arises when sellers find themselves each occupying a different step on the supply schedule, as shown in the lower right panel of Figure 2. In this case, we would expect a single seller to service the market in any period, and for sellers to rotate contracts across periods. Identify the low cost seller as seller $j$. Then one equilibrium strategy would be for each seller $i \neq j$ to bid $B_{i}\left(c_{k}, 4\right), k=\{b, c, d\}$ and for seller $j$ to bid $B_{i}\left(c_{b}-\varepsilon, 4\right)$. Within a period, only the seller $j$ realizes positive earnings. Since any bid reduction below $c_{b}-\varepsilon$ will reduce earnings on certain-to-sell units, and any bid increase will reduce sales to zero, this strategy is a Nash equilibrium for the stage game. ${ }^{11}$

Importantly, quantity rotations are far from the only outcome that can arise in this game. Sellers, for example, might simultaneously occupy different steps on the supply schedule, giving each seller a single unit at each cost step. A static equilibrium in this case would parallel exactly the equilibrium for the set cost design, shown above in Figure 1. A large variety of asymmetric marketsharing arrangements are also possible, and pricing strategies may exist that also make many or all of these patterns consistent with equilibrium behavior. 
Our primary interest, however, is to construct an environment where quantity rotations are consistent with non-collusive equilibrium behavior. The relatively low likelihood of tied bids in the early periods of an market in the endogenous cost design suggests that, as a behavioral matter, a quantity rotation outcome may be observed most frequently. Nevertheless, sellers may prefer some market-sharing outcome if there is any uncertainty about the duration of the market. The buyer's tie-breaking rule may also affect selected sales patterns. A fixed purchase tiebreaker virtually assures a market rotation outcome, while a rotating purchase tiebreaker makes heterogeneous costs and market sharing, at least marginally more likely.

\section{$\underline{\text { Efficient Conspiracies }}$}

Now consider the behavioral patterns that might be anticipated in each of these cost regimes under conspiratorial conditions. We confine our attention to "weak" conspiracies where side payments are not possible, but also suppose that both games are repeated indefinitely. Standard folk theorem results suggest that virtually any bid configuration where all sellers receive supracompetitive earnings can be supported via trigger strategies when the bidding process is repeated indefinitely. ${ }^{12}$ Given opportunities for explicit communication, monitoring presents perhaps the most prominent problem associated with implementing and maintaining collusive arrangements in indefinitely repeated environments. For this reason we focus our attention on the outcomes to be expected in light of the capacity of sellers to effectively monitor agreements in each environment. Notice, however, that in most relevant naturally occurring environments, as well as in the experiment that follows, monitoring problems are more pronounced than analysis of a fullinformation model suggests. When sellers have incomplete cost and demand information, the problems of implementing and maintaining conspiracies become intertwined with the problem of searching out a satisfactorily profitable outcome. 
In the set cost design illustrated in Figure 1, a variety of collusive arrangements are possible, but only the single outcome where each seller offers a single unit at price $r$ is fully efficient. The potential success of such an arrangement is sensitive to auction procedures. If the buyer provides full information regarding the identity of the seller from whom each unit was purchased, then the efficient conspiracy is fully monitorable. That is, the conspiracy is monitorable when each seller $i$ is informed of $\left(p_{j}, q_{j}\right)$ for every $j$, where $q_{j} \leq \hat{q}_{j}$ denotes the quantity sold. However, if the buyer only informs each seller $i$ of $p_{j}$ for every $j$, monitoring defections from the efficient conspiracy becomes more difficult (although, as we observe below, efficient conspiracies are not impossible in this case). Absent full disclosure of sales information, the most obviously monitorable scheme is an inefficient sales rotation. ${ }^{13}$

In the endogenous cost regime, a variety of collusive arrangements are also possible. Unlike the set cost design, however, all of these arrangements can be fully efficient, given appropriate underlying costs. Market rotations are perhaps the most likely, since they can be fully monitored even without disclosure of sales information. (Price postings clearly indicate any defections from a scheme to rotate sales across periods.) However, other outcomes may be monitorable, and have some appeal. In particular, other things constant, uncertainty about the final period might generate a symmetric market-sharing outcome, where all sellers posted the same price each period. As with the set cost design, this arrangement is most easily monitored if the buyer fully discloses purchase information each period.

\section{EXPERIMENT DESIGN AND PROCEDURES}

To evaluate the relationship between bid patterns and collusive behavior, we conducted the following experiment using 16 quadropolies. Each market session consists of 40 trading periods, and is organized under a variant of posted-offer trading rules appropriate to a procurement auction 
context. To mitigate potential "end game effects," the subjects were not informed in advance of the final period.

Each trading period consists of a two-part sequence. First, sellers privately submit sealed bids, which consist of a price and a discrete maximum quantity offer. Sellers are unrestricted in their price choices (although the possibility of price increments finer than one cent was not emphasized), and production is to-order in the sense that sellers incur costs only when a unit is sold. Once bids are submitted, a buying sequence begins. After the monitor announces publicly the bid prices (but not the offer quantities), an automated purchasing authority makes all purchases possible without incurring a loss. The buyer purchases mechanistically, buying the lowest priced units first. Following the purchasing sequence sellers calculate their earnings prior to making pricing decisions for the subsequent trading period.

Eight of the 16 sessions use the set cost regime in Figure 1, while the remaining eight sessions use the endogenous cost regime shown in Figure 2. In either case $c_{b}=x, c_{a}=-45+x, c_{c}=$ $30+x, c_{d}=45+x$, and $r=65+x$. For the first sequence of periods (1-20) $x=125$ or 165 , and for the second sequence of periods (21-40) $x$ changed to the other value. For example, if $x=165$ in the periods $1-20$, then for periods $31-40, x=125$. The initial choice of $x$ varies evenly across sessions. Demand steps above $r$ increase in 10 -cent increments to $75+x, 85+x$ and $95+x$. Thus, a total surplus of 500 cents is available each period. Per unit earnings range from 45 cents in the competitive outcome to 110 cents in an efficient conspiracy. To generate the period-specific cost schedules in the endogenous cost design, a monitor inputs the price and quantity decisions into a spreadsheet at the end of each period. A series of macros generates the appropriate new schedules, which are then printed and passed out to each seller.

The limited number of sellers, and the symmetry of their cost structures are factors that tend to facilitate conspiratorial arrangements. In an effort to improve critical parallels between the 
laboratory environment and relevant natural contexts, we complicate the market environment in some other respects. In particular, the variation in $x$ across session sequences, as well as the demand steps above $r$ are imposed to make the joint profit maximizing outcome nontransparent. Further, cost and demand information is not provided as public information. Absent full cost and demand information, sellers will likely have different prior beliefs, making collusion more difficult. Thus, as is typically the case in relevant naturally occurring contexts, our experiment evaluates environments where sellers do not have information sufficient to calculate reference equilibrium predictions.

Within each cost regime, sessions are evenly divided into treatments with and without communication opportunities. In the "communication" sessions, sellers are given three or four minutes to talk about the market at the beginning of the session, and again in four period intervals throughout the session. The discussions were unstructured, and the sellers could talk about any aspect of the market they wished, with the following exceptions: (1) side payments and physical threats are prohibited; (2) sellers may not discuss quantitative information about costs or capacities; (3) sellers may not discuss actions or outcomes in previous periods that were not publicly observable; and (4) sellers are under no obligation to comply with the terms of any agreement reached.

Except for the fact that participants could communicate only every fourth period, rather than after every period, communications conditions are those used previously by Davis and Holt (1998). ${ }^{14}$ Although these restrictions may be somewhat more rigid than is applicable in some relevant natural contexts, they usefully construct a controlled circumstance where the monitoring of conspiratorial arrangements is imperfect. The restrictions allow laboratory participants to defect from agreements without either lying explicitly, or violating social norms about verbal commitments. To ensure that participants did not violate the communications restrictions, 
participants were instructed to cover their record sheets prior to backing out of their booths, and a monitor listened to the discussions. ${ }^{15}$

Given the sensitivity of both collusive and non-collusive predictions to details regarding buyer practices, elements of buyer purchasing practices are blocked within sessions. In each of the no-communication sessions the buyer fully discloses information regarding the identity of the seller from whom each unit is purchased. However, we use two tiebreakers: a rotating purchase rule and a fixed purchase rule. Under the rotating purchase rule, the buyer divides purchases as equally as possible among all sellers posting the same price. With the fixed purchase rule the buyer randomly selects one of the tied sellers posting the same price and makes as many purchases as possible from this seller prior to switching to another seller. The initial rule used is rotated across sessions. Then after period 20 in each session the standing rule is changed for the remainder of the session.

The fixed purchase tiebreaker is used throughout the communication sessions, but two information disclosure conditions are rotated within sessions. In a full disclosure condition, the buyer publicly announces the identity of the seller from whom each unit was purchased. In a no disclosure condition, the buyer does not publicly disclose the number of units sold by each seller. Parallel to the treatment of tiebreaking rules in the no-communication markets, the initial disclosure condition is rotated across communication sessions. Then, after period 20 the standing condition is changed for the remainder of the session.

Table 1 summarizes the experimental treatments. The left columns of Tables 2 to 4 identify individual sessions via combinations of the treatment identifiers listed in Table 1: The initial " $c$ " or " $n$ " entry indicates that communications either are or are not allowed. The second entry " $s$ " or " $e$ " indicates the set cost and endogenous cost regimes, respectively. The third entry indicates changes in tie-breaking or sales disclosure rules, depending on the communications condition. In the nocommunications sessions combinations $f r$ and $r f$ indicate the order of the tie-breaker in 20 period 
sequences, with " $r$ " indicating a rotating purchase tie-breaker and " $f$ ' indicating a fixed purchase tie breaker. In the communications sessions the letters $i d$ and $d i$ combinations indicate the order of the disclosure rule in 20 period sequences, with " $d$ " signifying full disclosure and " $i$ " incomplete disclosure. Each identifier ends with a number that distinguishes sessions within treatments. Thus, for example, the identifier $n-s-f r l$, listed in the first row of Table 2 indicates the first of two sessions conducted in the set cost design without communication opportunities, where, for periods 1-20 the fixed purchase tiebreaker is used, and the rotating purchase tiebreaker for periods 21-40. Similarly, identifier $c$-e-id2 listed in the bottom row of the table represents the second of two endogenous cost sessions where communications were allowed. For the first 20 periods sellers were not told sales quantities, while in periods 21-40 the buyer fully disclosed the quantities sold by each seller.

As is evident from Table 1, given two designs, two tie-breaking rules, two information conditions and two communications conditions, $2^{4}=16$ different treatment combinations are possible. Parsimony considerations dictate that we restrict our attention to the eight treatment combinations described above. The omitted treatment combinations are by far the least interesting: In the communication sessions we do not examine the effects of changing tie-breaking rules, because a rotating purchase tie-breaker enhances the monitorability of price-based conspiracies, even absent quantity information. In the no communication sessions we do not examine the effects of changing information conditions, since there is reason to suppose that such information affects decisions. ${ }^{16}$

Sixty-four undergraduate student volunteers recruited from economics courses at Middlebury College participated in the experiment. Some students had participated previously in a market experiment, but in a different design, and with different trading rules. No one participated in more than one of the sessions reported in this experiment. At the outset of each session, participants were seated at visually isolated booths, and a monitor read instructions aloud as the participants 
followed along on a printed copy of their own. The market sessions were conducted manually with the assistance of a laptop computer and a printer that the monitor used to record earnings and (for the endogenous cost sessions) to determine cost schedules for each period.

Following the instructions, the first period began, and participants made price and quantity decisions, and updated their record sheets each trading period, as described above. After period 40, the monitor announced that the experiment ended, and participants were paid privately and left individually. Participants received $\$ 6$ for making their appointment, and salient earnings ranged from $\$ 14.50$ to $\$ 34.00$ for the two-hour sessions. ${ }^{17}$ Average earnings were $\$ 22.94$.

\section{RESULTS}

The mean contract prices for the set cost and endogenous cost designs, shown respectively in Figures 3 and 4, illustrate several primary results of the experiment. Each figure consists of four vertical strips, which list mean contract prices in 10 period segments. Within strips, the vertically aligned ' $\diamond$ ' and ' $\diamond$ ' markers illustrate mean prices in no-communication sessions, while the vertically aligned ' $O$ ' and ' $O$ ' markers illustrate mean prices in corresponding communication sessions. For each column of diamonds or circles, the horizontal bars '- ' indicate the 10-period mean price for the treatment. Comparing treatment means across communication conditions, observe that communication opportunities generate higher mean prices throughout both the set cost and endogenous cost markets. Nevertheless, outcomes in the communication sessions of a segment tend to be more variable than in its no-communication counterpart, and prices clearly separate only in the latter periods. The deviations of mean transactions prices from the competitive price $P_{c}$, shown in Table 2 support this observation quantitatively. In both the set cost sessions, summarized in the upper half of the table, and in the endogenous cost sessions, summarized in the lower half of the table, the bolded 10-period 
treatment mean prices are uniformly higher with communication than without communication. However, as indicated by the $a$ and $b$ superscripts printed aside the treatment means, these differences are significant only for periods 31-40 in the set cost markets, and for periods 21-30 and 31-40 in the endogenous cost markets, using a Mann-Whitney test. Nevertheless, observe that in the last 10-period segments mean differences are large: $45.3 \phi$ across set cost treatments, and $52.5 \varnothing$ across endogenous cost treatments, both reasonably near the predicted difference between $P_{m}$ and $P_{c}$ of $65 \varnothing$.

The monopoly effectiveness index values shown in Table 3 illustrate the impact of communications on profits. ${ }^{18}$ As with the price data, while $M$ values are uniformly higher on average in communication treatments than their no-communication counterparts, the differences are statistically significant only in the final session segments. Again, however, observe that that toward the end of the sessions, the differences become quite large: The .70 difference in $M$ values across communication conditions in the set cost markets and the .80 difference across communication conditions in the endogenous cost markets are both near the 1.00 change $M$ in values associated with a movement from the competitive outcome to joint profit maximization.

The persistent variability of prices and monopoly effectiveness values throughout much of the communication sessions suggest that successfully raising prices via a conspiracy is a nontrivial task in our environments. Nevertheless, by the end of each communication session sellers had implemented a reasonably effective collusive arrangement. Even the low and stable prices in the latter part of session $c-s-n f 2$ (highlighted in Figure 3 with an asterisk) were the result of a stable (but non-optimizing) agreement among the sellers. ${ }^{19}$ In summary, although organizing effective conspiracies is not a trivial matter, communications significantly affect market performance. In both the set cost regime and in the endogenous cost regime, 
communication opportunities eventually increase transaction prices and monopoly effectiveness index values.

A second result apparent Figures 3 and 4 is that alternating the buyer purchasing rules does not prominently affect market performance in no communication markets, and that changing information disclosure does not affect performance in markets with communications. In the nocommunication markets, session segments with presumably more stable rotating purchase tiebreakers (' $\diamond$ 's) are not closer to $P_{c}$ than the segments using the fixed purchase tiebreaker (' $\diamond$ 's). Similarly, in the communication sessions, the more easily monitorable full disclosure segments ('○'s) are not obviously closer to $P_{m}$ than incomplete disclosure segments ('O's).

The apparent unimportance of both tie-breaking rule changes and sales quantity disclosure conditions are most probably artifacts of the environments examined here. In the nocommunication markets, the absence of an effect in the endogenous cost sessions is unsurprising, since the conjectured effect of changing tie-breaking rules was fairly weak. More surprising is the unimportance of tie-breaking rules in the set cost design. As suggested by the heterogeneous deviations of mean prices from $P_{c}$ shown in the upper portion of Table 2, persistent price variability was observed in all no communication set cost markets. The upper portion of Table 4 presents some relevant summary information for periods 31-40. Notice, in column (3) of this table that of 40 possible periods, sellers posted identical prices only three times. Further, two of these instances occurred in markets using a fixed-purchase rule.

Two factors might explain the persistent heterogeneity of prices in sessions conducted with the rotating cost tie-breaker. First, Nash equilibria may not be precise predictors of behavior in instances like the present one where sellers are indifferent between playing the equilibrium strategy, and an alternative strategy where they offer only units that could generate positive profits. Offering only units that yield positive earnings breaks the equilibrium at $P_{c}$, and induces randomizing 
behavior identical to that predicted in the under the fixed-purchase tie-breaker. Second, sellers may be drawn to static equilibrium predictions, but perceive an effective minimum bid increment. As observed in section II above, this creates additional pure-strategy equilibria near $P_{c}$, and persistent bid variability might be due to equilibrium selection problems.

Examining bid decisions in the latter portions of sessions tentatively suggests that the observed heterogeneity in set cost sessions under a rotating purchase rule may primarily be an equilibrium selection problem. If the persistent price variability was primarily a result of sellers failing to offer zero profit units, bidding behavior should not differ distinguishably across tiebreaking rule changes. However, as suggested by the frequency distributions of bids in periods 3140 for the no communication set cost sessions shown in Figure 5, bids do appear to differ across tiebreaking rules: The black bars, illustrating bids for sessions using a rotating purchase tie-breaker, are more tightly clustered about $P_{c}$ than the white bars, which illustrate comparable bids for sessions using a fixed purchase tie-breaker. ${ }^{20}$ That sellers never submitted a bid increment finer than $1 \phi$ enhances the likelihood that this remaining bid variability was due to equilibrium selection problems. We emphasize that the multiplicity of pure-strategy equilibria with the rotating cost tiebreaker is not a design shortcoming, since in any natural circumstance sellers face an effective minimum increment when bidding. Rather, we suggest it that is a reason why identical pricing may be difficult to obtain in procurement auctions absent some sort of bid coordination.

In the communication sessions, the absence of an information-disclosure effect may also be a consequence of the procurement contexts examined. As mentioned above, in our endogenous cost markets, full disclosure of sales information is not necessary for monitoring efficient conspiracies if sellers adopt a quantity-rotation scheme. Further, sales quantity disclosure may be unnecessary to effectively maintain an efficient market-sharing arrangement. Although sellers could not explicitly communicate quantitative outcomes that were not publicly observable, they 
could qualitatively indicate that they were "happy" with results or not. In a small group, where a limited number of units are repeatedly bid for in an indefinitely repeated game, such qualitative information may suffice. "Happy," for example, likely indicates a sale. Thus, the existence of an "unhappy" participant indicates either that the price is too high or that someone has defected. A clever defector may be able to disguise their actions absent full disclosure. However, given repeated interactions, the defector must lie more and more egregiously. Further, even if the misrepresentations are believed, sellers must conclude that demand is too high, causing the agreed upon prices (and profits) to fall.

In summary then, in no-communication environments the tie-breaking rule does not appear to affect convergence to competitive price $P_{c}$, and in communication environments, the publicity of sales information does not appear to affect capacity of conspirators to achieve the joint profit maximizing price $P_{m}$.

Due to the large number of periods needed to implement effective arrangements, in what follows we concentrate on the final 10 periods of each session, as a means of isolating the behavioral differences between stable conspiracies and competitive firms. This second result allows us to focus on these final periods without attending further to the effects of altering the publicity of sales conditions and tie-breaking rules.

Consider now the ability to detect conspiracies from patterns of pricing and market sharing. We first discuss the set cost design. The important result here is that despite the prediction of identical prices and market sharing in a unique Nash equilibrium without communication, such an outcome is observed virtually only with communication opportunities.

The incidences of identical prices and market sharing for the last 10 periods of the market, summarized in columns (3) and (4) of Table 4, provide the relevant evidence. As observed above, in the no-communication sessions, sellers manage to post identical prices in only three of the forty 
possible periods in the four sessions, combined. Further, as seen in column (4), sellers share the market in no more than four periods of any session. In contrast, both identical prices and market sharing pervade the set cost sessions with communication. In three of the four markets with communication opportunities, sellers post identical prices in at least nine of ten periods, and sellers share the market in at least eight of ten periods. Using a Mann-Whitney test, the differences in the incidence of identical prices and market sharing across the communication condition are statistically significant at a $97.5 \%$ level. $^{21}$ In summary, "suspicious" behavior is indeed indicative of a conspiracy in the set cost regime. Market sharing, and particularly identical prices are much more commonly observed with communication than without communication

Consider now the detectability of conspiratorial arrangements in the endogenous cost design. Notice in column (5) in the bottom two row-blocks of Table 4 that market rotations occur frequently both with the conspiracies in the communication treatment, and with the non-cooperative behavior in the no communication sessions. ${ }^{22}$ Nevertheless, the existence of a conspiracy is easily detectable in the presence of market rotations. In no-communications sessions, bids tend to move with changes in costs. In contrast, with the communications sessions, bid a high common price in an effort to "stay out of the way" of the assigned winning seller.

Identifying differences in the pattern of losing bidders is key to the statistical approach used by Porter and Zona $(1993,1997)$ to identify road construction and school milk market conspiracies. The simple correlations between losing bids and costs, printed in column (6) of Table 4, illustrate the effectiveness of this technique, when markets are characterized by market rotations. In the no communication sessions with market rotations ( $n$-e-frl and $n$-e-rfl) the correlation between costs and bids is .46 and .68 . In the three endogenous cost sessions with communication and market rotations ( $c-e-d i 1, c-e-d i 2$ and $c-e-i d 2)$, the correlation between costs and postings without sales bids is noticeably lower at $0,0.26$ and 0 , respectively. Thus, market rotations occur in the endogenous 
cost regime, both with and without communication opportunities. However, collusive and noncollusive markets are often discernable in that the correlation between costs and the losing bids tends to break down in the collusive sessions.

Although this approach is promising, a full consideration of results in the endogenous cost sessions suggests two important qualifications that must made in its application. First, if outcomes other than quantity rotations are feasible, the correlation between costs and losing postings can quickly become uninformative. In the no-communication endogenous cost sessions the correlations weaken as sellers' cost structures become heterogeneous within periods, because the sellers post a single price to offer multiple units with different costs. Session $n$-e-rf2, with $\rho=.20$ is a relevant example. In endogenous cost markets with communication, market sharing among sellers may generate too few losing bids to draw any meaningful correlation. Session $c$-e-idl illustrates. In this session sellers commenced a conspiratorial arrangement with market sharing only in period 33, after their penultimate meeting. For these final eight periods only three postings resulted in no sales. The accident that the seller with the highest average costs happens to post the highest of the losing prices drives an almost perfect correlation between costs and posted prices for those eight periods, as reflected parenthetically reported $\rho=.98$ for this session.

Second, even when a conspiracy is characterized by quantity rotations, relatively minor changes in seller behavior can prominently affect summary statistics. For example, in $c$-e-di2, sellers used the final digits of their bids to simplify price searching. As a general rule, the sellers agreed to post a common price of 300 in each period, except in the period where it was their turn to take the market. However, in each period after taking the market, the now high cost seller added the number of units sold in the preceding period to 300. For example, following a winning posting of $r$ +1 , the seller would post 303 in the subsequent period to indicate that three units were purchased at 
that price. $^{23}$ Notice in column (6) that this minor change in the bid pattern raises the correlation from 0 to .26 .

An even more severe problem arises in $c$-e-dil. In this market, anticipating that period 40 would be the end of the session, seller $S 3$ defected from the rotating quantity agreement and took the market in period 40 with the highest costs. As indicated by the parenthetical correlation printed in column (6), this single outlier changes the correlation from 0 to $.69 .^{24}$

\section{DISCUSSION}

This paper examines the relationships between communications conditions, the underlying structure of costs and conspiratorial behavior. We find that the powerful effects of explicit communications on conspiratorial behavior observed in previously in other posted-offer type markets extends to the markets of longer duration, and with more limited opportunities for discussion, examined here. A novel feature of our experimental results is the somewhat curious finding that neither details affecting the static equilibria in non-cooperative environments, nor details affecting the monitorability of conspiratorial arrangements affect performance. We attribute these results to the procurement-type bidding contexts that we tried to emulate. In the set cost markets without communication opportunities, changing tie-breaking rules does not affect behavior, despite affecting the existence of pure-strategy Nash equilibria. However, in a multi-unit procurement context, we observe that any limitation on the bid grid (explicit or implicit) creates multiple equilibria. Equilibrium selection problems appear to explain some of the persistent variability.

In markets with communication opportunities, full disclosure of sales information does not appear to affect collusive arrangements, despite the fact that conspiracies were hard to arrange, and defection was a persistent problem. Here we suspect that sellers were effectively able to convey 
satisfaction or dissatisfaction with results absent a public reporting of sales information. This result is also, a consequence that we suspect may extend to parallel natural contexts.

A second novel result is that the underlying cost structure conspicuously influences the nature of conspiratorial agreements. In a set cost environment that represents perhaps a "best shot" case for observing identical pricing and market sharing absent collusion in a procurement-type context, identical prices and, to a lesser extent, market sharing are indeed "suspect" behavior. Close examination of our set cost design suggests that there are theoretical and behavioral reasons to view with some suspicion claims that identical prices are purely a result of non-cooperative behavior in a procurement auction context. $^{25}$

In markets with an endogenous cost structure, quantity rotations are observed, both with and without communication. But while quantity rotations are not indicative of collusive behavior, the pattern of losing bids represents a promising device for identifying conspiracies in the presence of quantity rotations. ${ }^{26}$

These results lead us to suggest a modified approach for identifying collusion from behavioral patterns: Conspirators do tend to exhibit patterns of behavior that differ from uncoordinated competitors. However, these patterns may be identified only with fairly precise information about the structure of particular markets. Thus, while econometric tools for identifying conspiratorial behavior may be useful in specific contexts, general market monitoring of the type recommended by Gallo (1977) are of doubtful use. ${ }^{27}$

Extensions of this work continue in two dimensions. First, we plan to examine the responses weak form conspirators to information that an authority is screening bids to detect conspiratorial behavior. As observed by LaCasse (1995), strong form conspirators can submit bids to a center that disguises behavior perfectly. Presumably the machinery needed to maintain such arrangements facilitates their detection. The responses of less perfectly organized conspirators to 
information that their behavior is being monitored is an open question of some interest. Second, we are exploring more carefully the robustness of the econometric devices developed by Porter and Zona (1993, 1997), Pesendorfer (1998) and others for detecting collusion. This second project involves introducing conspiratorial opportunities in a market of fairly long duration, where random cost and demand shocks create enough variability in predicted outcomes to allow a meaningful application of these techniques. Applying these methods to markets where actual costs, as well as the controlled presence or absence of conspiracies will allow some critical insight into the accuracy and applicability of these tools. 


\section{REFERENCES}

Anton, James J. and Dennis A. Yao. "Coordination in Split Award Auctions.” Quarterly Journal of Economics, 107, 1992, 681-707.

Armentano, D. Antitrust and Monopoly: Anatomy of a Policy Failure, 2nd ed. New York: Wiley, 1990.

Cason, Timothy N. "Cheap Talk Price Signaling in Laboratory Markets.” Information Economics and Policy, 7, 1995, 183-204.

Cason, Timothy N., and Douglas D. Davis. "Price Communications in Laboratory Markets: An Experimental Investigation.” Review of Industrial Organization, 10, 1995, 769-787.

Cohen, Mark, and David Scheffman. “The Antitrust Sentencing Guideline: Is the Punishment Worth the Costs?" Journal of Criminal Law, 27, 1989, 330-336.

Comanor, William S., and Mark A. Schankerman. "Identical Bids and Cartel Behavior." The Bell Journal of Economics, 7, 1976, 281-286.

Cook, P.W. "Fact and Fancy on Identical Bids.” Harvard Business Review, 41, 1963, 67-72.

Crampton, Peter, and Jesse Schwartz. "Collusive Bidding: Lessons from the FCC Spectrum Auctions.” Working paper, University of Maryland, 1998.

Davis, Douglas D., and Charles A. Holt. "Conspiracies and Secret Discounts in Laboratory Markets.” Economic Journal, 108, 1998, 736-56.

Davis, Douglas D. and Bart J. Wilson. "Firm-Specific Cost Savings and Market Power." Economic Theory, 16(3), 2000, 545-565.

Froeb, Luke M., Robert A. Koyak, and Gregory J. Werden. "What is the Effect of Bid Rigging on Prices?" Economics Letters, 42, 1993, 419-23.

Gallo, Joseph. C. "A Computerized Approach to Detect Collusion in the Sealed-Bid Market." The Antitrust Bulletin, 22, 1977, 593-620. 
Hendricks, Kenneth, and Robert Porter. "Collusion in Auctions." Annales d'Economie et de Statistique. 0(15-16), 1989, 217-30.

Holt, Charles A., and Douglas D. Davis. "The Effects of Non-Binding Price Announcements on Posted-Offer Markets.” Economics Letters, 34, 1990, 307-310.

Holt, Charles A., and Francisco Solis-Soberon, "The Calculation of Mixed-Strategy Equilibria in Posted Offer Markets." in Research in Experimental Economics, Vol. 5. R.M. Isaac, ed. Greenwich: JAI Press, 1992.

Isaac, R. Mark, and Charles R. Plott. “The Opportunity for Conspiracy in Restraint of Trade.” Journal of Economic Behavior and Organization, 2, 1981, 1-30.

Isaac, R. Mark, Ramey, Valerie, and Williams, Arlington. “The Effects of Market Organization on Conspiracies in Restraint of Trade." Journal of Economic Behavior and Organization, 5, $1984,191-222$.

Isaac, R. Mark, and James Walker. "Information and Conspiracy in Sealed Bid Auctions.” Journal of Economic Behavior and Organization, 6 , 1985, 139-59.

Kuhlman, John M. "Nature and Significance of Price Fixing Rings.” Antitrust Law and Economics Review, 2, 1969, 69-82.

Lang, Kevin, and Robert W. Rosenthal. "The Contractors' Game.” RAND Journal of Economics, 22, 1991, 329-38.

LaCasse, Chantale "Bid Rigging and the Threat of Government Prosecution." RAND Journal of Economics, 26, 1995, 398-417.

Marshall, Robert C., and Michael J. Muerer. "The Economics of Bidder Collusion.” in Game Theory and Business Applications, K. Chatterjee ed., New York, Kluwer, 1998.

Marvel, H., J. Netter and A. Robinson. "Price Fixing and Civil Damages: An Economic Analysis." Stanford Law Review 40, 1988, 561-75. 
McAfee, R. Preston and John McMillan. "Bidding Rings.” American Economic Review, 82, 1992, 579-99.

Mund Victor A. “Identical Bid Prices.” Journal of Political Economy, 68, 1992, 150-69.

Pesendorfer, Martin. "A Study of Collusion in First-Price Auctions." Working paper, Yale University, 1998.

Porter Robert H., and J. Douglas Zona. "Ohio School Milk Markets: An Analysis of Bidding." Working Paper, NBER, 1997.

Porter, Robert H., and J. Douglas Zona. "Detection of Bid Rigging in Procurement Auctions." Journal of Political Economy 101, 1993, 79-99.

Posner, Richard. "Oligopoly and the Antitrust Laws: A Suggested Approach." Stanford Law Review, 21, 1969, 1562-1606.

Saijo, Tatsuyoshi, Masashi Une, and Toru Yamaguchi. “'Dango' Experiments.” Journal of the Japanese and International Economies, 10, 1996, 1-11.

Werden, Gregory J. "Price-Fixing and Civil Damages: Setting the Record Straight." The Antitrust Bulletin, 24, 1989, 307-35.

Zona, J. Douglas. "Bid Rigging and the Competitive Bidding Process: Theory and Evidence." Ph.D. dissertation, State University of New York at Stony Brook, 1986. 


\section{Notes}

*Virginia Commonwealth University and the University of Arizona, respectively. We thank for helpful comments Kenneth Chan, David Harless, Kevin McCabe, Edward Millner, Stuart Mestelman, Andrew Mueller, Robert Reilly, four anonymous referees and seminar participants at McMaster University, the University of Arizona, the University of Mississippi and a session at the 1999 ESA/PCS meetings. The usual disclaimer applies. Financial assistance from the National Science Foundation and from the Virginia Commonwealth University Faculty Excellence Fund is gratefully acknowledged. The data reported and the experiment instructions are available at http://www.bus.olemiss.edu/ddavis.

${ }^{1}$ McAfee and McMillan (1992) show that identical bids are the most efficient conspiratorial arrangement possible in a first price sealed bid auction, when side payments are not possible.

${ }^{2}$ The model not only predicts market division, but sellers may post discriminatory bids for items with identical costs, a result that Posner (1969) considers to be particularly indicative of collusion.

${ }^{3}$ In a different context, where the alleged conspirators did not bid unless it was their turn to win the auction, Porter and Zona (1997) identify bid rigging from the pattern of vendors refraining from bidding. These detection schemes provide rather weak prescriptions for enforcement, since cartel members can alter bid patterns if they are aware that the government views a particular pattern as suspect. We note, however, that the alternative patterns conspirators might select under such conditions is an open question.

4 For example, nearly all the papers referenced in the introduction pertain to collusion in procurement auctions. 
${ }^{5}$ Measuring marginal cost is the weakest link of any empirical field study, and we will demonstrate in this paper that the nature of costs clearly shapes the character of conspiratorial agreements. Field studies often rely on proxy measures of costs.

${ }^{6}$ Ignore for the moment the demand steps above $r$. They are set so as to not affect equilibrium predictions, and are introduced in the laboratory implementation of these models only to make the joint profit-maximizing outcome non-transparent.

${ }^{7}$ A static Nash equilibrium where any seller's earnings strictly decrease with any deviation from the equilibrium strategy can be generated in a posted-offer market, but in designs that are doubtfully relevant to a procurement auction. For example, Davis and Wilson (2000) construct a design where sellers exhaust supply at the competitive outcome and where demand conditions limit price increases.

${ }^{8}$ Suppose that all sellers submit $B\left(P_{c}+2,2\right)$. Thus, eight units are offered in aggregate, and for each seller $i$, the sales quantity $q_{i}=1$ and earnings are $c_{b}-c_{a}+2$. The excess supply of four units implies that any unilateral price increase reduces earnings to zero. Although with any price reduction $q_{i}=2$, earnings cannot increase. At best, a $1 \phi$ price reduction leaves earnings unchanged. (In this case, the penny lost from the price cut on the previously sold unit just offsets the penny increase from selling an additional unit.) Symmetric strategy $B\left(P_{c}+1,2\right)$ can be shown to be a Nash equilibrium via identical reasoning.

${ }^{9}$ With the parameters used in our experiment, the static equilibrium for this game involves randomization over the range $P_{c}$ up to the joint profit-maximizing price, $r$. Equilibrium randomizing distributions can be calculated via the method outlined by Holt and Solis-Soberon (1992).

${ }^{10}$ We use this "endogenous cost design" label with some caution. As observed by an anonymous referee, this label is potentially misleading, in the sense that within any period costs are fixed. 
Nevertheless, costs are endogenous in the sense that across periods seller choices determine both the individual and the aggregate structure of costs.

11 This equilibrium is not an entirely satisfactory solution. In particular, it fails trembling hand perfection. To see this, suppose that costs for $S 1, S 2, S 3$, and $S 4$ are ordered from lowest to highest. In the event that $S 1$ deviates from posting a bid $B_{I}\left(c_{b}-\varepsilon, 4\right), S 2$ would regret submitting $B_{2}\left(c_{b}, 4\right)$, because in this case $S 2$ would exchange the positive profits available in the subsequent period for sales at zero-profit this period. Seller $S 2$ will change his or her price even as the probability of a "tremble" by $S 1$ goes to zero, since S2 gives up nothing by raising prices. This observation suggests that $S 1$ may bid above $c_{b}-\varepsilon$ absent conspiracies. Thus, to the extent that trembles are relevant to this game, supra-competitive prices may be observed in a non-collusive market.

${ }^{12}$ In fact, trigger strategies could support supra-competitive prices in either of the baseline environments without any direct communication. As a practical matter, however, such agreements are very difficult to arrange without explicit discussions, even when the environment contains features that would facilitate cooperative behavior. See, for example, Holt and Davis (1990), Cason and Davis (1995) and Cason, (1995).

${ }^{13}$ A sales rotation scheme is inefficient because costs for three of the four units sold each period exceed $c_{a}$. Given our parameters the costs of quantity rotations is quite high: Per period market efficiency is $58 \%$, and at best, expected per period earnings exceed competitive earnings by only $27 \%$. In contrast, seller earnings may exceed the competitive level by $100 \%$ in a conspiracy with market sharing.

${ }^{14}$ Restricting discussions to four-period intervals permits considerably less communication than was available to participants in the previous collusion experiments discussed in the introduction. In addition to our interest in focusing participants' attention on the monitorability of arrangements, a procedural factor motivates this design choice. We are interested in developing a mechanism for 
generating longer data series than has previously been generated for conspiratorial markets. Per period meetings are too time intensive to be consistent with this goal. For the most part, the administration of our communications sessions parallels procedures used in the bulk of the previous studies. Isaac and Plott (1981), Isaac, Ramey and Williams (1984), and Isaac and Williams (1985) all prohibited side payments, physical threats and cardinal revelation of costs and quantities, as we did. Our additional prohibition on discussing non-observable aspects of previous outcomes, and our emphasis that participants were not obligated to comply with the terms of any agreement were intended to make defections of the sort observed by Davis and Holt (1998) a possibility. Finally note that Siajo, Une and Yamaguchi (1996) allowed considerably more in latitude in participants' communications than in any of the other studies referenced here. These essentially unrestricted communications were consistent with the strong form conspiratorial arrangements that were the focus of their investigation.

${ }^{15}$ In one or two instances the monitor had to remind participants that certain variables could not be discussed. In general participants asked the monitor about the admissibility of a topic prior to mentioning it. All such issues of clarification occurred in the initial meetings of a session.

16 Absent communication opportunities, equilibria are insensitive to the buyer's disclosure rule. We uniformly used full disclosure in the no-communication treatment to improve the chances of observing the competitive prediction. We believed that the common observation of a symmetric outcome would encourage stability.

${ }^{17}$ To ensure that enough participants appeared in each session, we over-recruited by one or more people. In the event that more than four participants met their appointment, the surplus students were designated as alternates. Alternates were paid a $\$ 10$ appearance fee and were invited to participate in a future session. 
${ }^{18} M=$ Index of Monopoly Effectiveness $=\frac{\text { Realized Industry Profit }- \text { Competitive Industry Profit }}{\text { Maximum Monopoly Profit }- \text { Competitve Industry Profit }}$.

19 In fact, these sellers were quite pleased to have come to the agreement that they achieved. Continual defections throughout the first portion of the session resulted in the very low prices, shown in Table 2. Earnings for these sellers increased rather substantially toward the end of the session. As seen in Table 3, $M$ values increased from an average of -.32 in periods 11-20 to .08 in periods $31-40$.

${ }^{20}$ Session specific effects drive some of the observed treatment differences shown in Figure 5. For example, in distinction to other sessions, sellers in $c$-s-rf2 sellers engaged in a considerable amount of price signaling, independent of the tie-breaking rule used. In periods 31-40 bids for this session are included in the fixed tie-breaker treatment. Nevertheless changing tie-breaking rules affects the variability of bids in all markets. For example, comparing periods $11-20$ and $31-40$ in all sessions, more bids were within two cents of $P_{c}$ in the segment using the rotating tie-breaker than in the segment using the fixed-purchase tie-breaker.

21 In each case the null hypothesis is that the presence of communication does not increase the incidence of the indicator. For both identical prices and periods of Market Sharing, $T=0$, which is less than $97.5 \%$ c.v. of 1 (4,4 d.f. 1-tailed test). Notice that the incidence of identical prices in periods 31-40 is higher in sessions with a full disclosure condition than for sessions with incomplete disclosure, an observation suggesting that providing sales quantity information might facilitate coordination. However, closer inspection of behavior in sessions $c$-s-dil and $c-s$-di2 undermines this hypothesis. Periods $31-40$ of session $c$-s-dil is particularly interesting. Here, after continuing (and observable defections), sellers adopted a sophisticated arrangement scheme to search out the joint profit-maximizing price at session's end. In their meetings after periods 32 and 36, sellers agreed to boost prices by 10 cents each period until one seller was left out of the market. Upon 
failing to make a sale, the excluded seller would return to the last price where all units sold. This would be the joint profit-maximizing price (within a range of 10 cents). In the subsequent period, all sellers would return to this price. The sellers carried out this plan flawlessly, resulting in the 9 periods of identical prices and 8 periods of market sharing shown in Table 4. Some defections did occur in periods $31-40$ of session $c-s-i d 2$. However, the defections were a continuation of defections that persisted throughout this session, both with complete and incomplete disclosure.

22 Market rotations are defined as the number of times when a single seller makes all sales in a period, and when another sellers sells all units in an adjacent period. For rotations longer than two, quantities must rotate among seller in sequence.

${ }^{23}$ Crampton and Schwartz (1998) document the use of trailing digits to relay market information in the FCC spectrum auctions. A related arrangement, which was discussed by sellers in $c$-e-di2, but not implemented would have generated a perfect correlation between non-winning bids and costs. Earlier in this session, one seller justified his repeated, monitorable defections with the claim that he forgot when it was his turn. To circumvent this problem, the sellers discussed a scheme where a seller would use the final digit of his bid to indicate his position in the rotation. For example, a bid of 304 would indicate that a seller had just taken the market and had highest costs. A bid of 303 would indicate next-to-highest costs, etc. This bid pattern is perfectly correlated with the temporal cost reductions.

${ }^{24}$ Recall that the final period was not disclosed in advance. Session $c$-e-dil was the only session where an obvious end-game effect was observed.

${ }^{25}$ Notice that we are not arguing here that identical prices cannot be observed absent cooperative behavior. (Indeed, in an alternative design, Davis and Wilson (2000) observed instances of identical pricing in the laboratory.) Rather, our claim is that in a procurement type context, where the buyer 
inelastically demands a limited number of units, identical pricing is unlikely. As noted by McAfee and McMillian (1992) identical prices are pervasive in procurement contracts.

${ }^{26}$ With good cost information, the analyst could presumably detect supra-competitive pricing by simply comparing price-cost markups. However, such cost information is typically not available, and the analyst must rely on instruments, such as capacity utilization or distance as instruments that may identify relative cost differences but perhaps not cost levels.

${ }^{27}$ This recommendation parallels Hendricks and Porter (1989). 
Table 1. Summary of Experimental Treatments

Treatment Variable

Communication Regime

Cost Design

Tie-breaking Rule
Description

With communication

With no communication

Set cost

Endogenous cost

Fixed purchase tiebreaker

Rotating purchase

tiebreaker
Mnemonic

c

$n$

$S$

$e$

Full disclosure

Incomplete disclosure $f$

$r$

$d$

$i$

Each of the 16 sessions in the experiment examined two treatments: The eight sessions without communications vary the tie-breaking rule across session halves ( $r f$ or $f r$ ), but always under the full disclosure condition $(d)$. The eight sessions with communications vary the disclosure conditions across session halves ( $i d$ or $d i$ ), always using using the fixed purchase tiebreaker $(f)$. 
Table 2. Price Deviations $\bar{P}-P_{c}$.

\begin{tabular}{|c|c|c|c|c|c|}
\hline & \multirow[t]{2}{*}{$\underline{\text { Session }}$} & \multicolumn{4}{|c|}{ Periods } \\
\hline & & $\underline{1-10}$ & $\underline{11-20}$ & $21-30$ & 31-40 \\
\hline \multicolumn{6}{|c|}{ Set Cost Markets } \\
\hline \multirow{5}{*}{$\begin{array}{c}\text { No } \\
\text { Commun- } \\
\text { ications }\end{array}$} & $n-s-f r l$ & -0.2 & -2.2 & 5.6 & -3.3 \\
\hline & $n-s-f r 2$ & 4.3 & -2.6 & -0.2 & 0.6 \\
\hline & $n-s-r f 1$ & -6.3 & 0.6 & -1.2 & -2.3 \\
\hline & $\underline{n-s-r f 2}$ & 10.2 & $\underline{10.7}$ & $\underline{17.4}$ & 9.1 \\
\hline & $n-s a v$ & 2.0 & 1.6 & 5.4 & $\overline{1.0}$ \\
\hline \multirow{5}{*}{$\begin{array}{l}\text { Commun- } \\
\text { ications }\end{array}$} & $c-s-d i l$ & 25.1 & 19.9 & -11.2 & 52.0 \\
\hline & $c-s-d i 2$ & 45.2 & 64.6 & 50.7 & 63.2 \\
\hline & $c-s-i d 1$ & 13.3 & 54.9 & 51.3 & 65.0 \\
\hline & $\underline{c-s-i d 2}$ & -3.4 & $\underline{-6.5}$ & $\underline{-0.9}$ & $\underline{5.0}$ \\
\hline & $\overline{c-s a v}$ & $\overline{20.1}$ & $\overline{33.2}$ & $\overline{22.5}$ & $\overline{46.3}^{a}$ \\
\hline \multicolumn{6}{|c|}{ Endogenous Cost Markets } \\
\hline \multirow{5}{*}{$\begin{array}{c}\text { No } \\
\text { Commun- } \\
\text { ications }\end{array}$} & $n-e-f r l$ & -8.2 & -2.6 & -10.1 & 14.4 \\
\hline & $n-e-f r 2$ & -28.4 & 4.5 & -1.8 & 7.5 \\
\hline & $n-e-r f 1$ & -14.0 & 0.7 & -7.4 & -2.3 \\
\hline & $\underline{n-e-r f 2}$ & -26.4 & -5.1 & -12.5 & $\underline{10.5}$ \\
\hline & $\overline{n-e} a v$ & $\overline{-19.3}$ & $\overline{-0.6}$ & -7.9 & $\overline{7.5}$ \\
\hline \multirow{5}{*}{$\begin{array}{l}\text { Commun- } \\
\text { ications }\end{array}$} & $c-e-d i l$ & 21.3 & 65.0 & 32.3 & 64.0 \\
\hline & $c-e-d i 2$ & -17.8 & 17.4 & 4.6 & 67.8 \\
\hline & $c-e-i d l$ & -28.3 & -4.8 & 18.3 & 43.3 \\
\hline & $\underline{c-e-i d 2}$ & -3.8 & $\underline{69.0}$ & 66.5 & $\underline{65.0}$ \\
\hline & $\overline{c-e a v .}$ & $\overline{-7.1}$ & $\overline{36.7}$ & 30.4 & $60.0^{b}$ \\
\hline
\end{tabular}


Table 3. Monopoly Effectiveness Index $M$ Values. $^{\text {a }}$

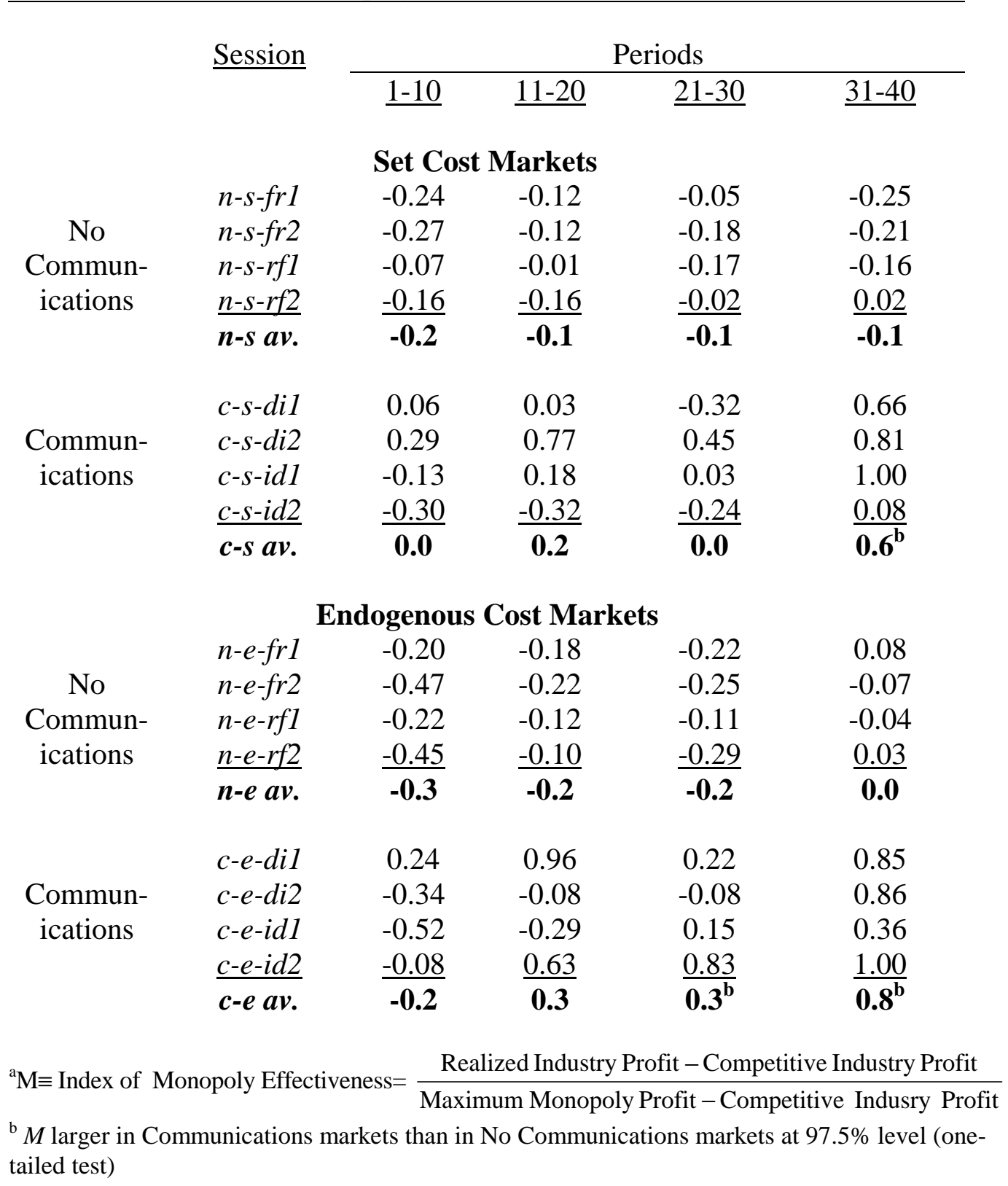


Table 4. Some Indicators of Collusion, Periods 31-40.

\begin{tabular}{|c|c|c|c|c|c|c|}
\hline & & & & Indicato & & \\
\hline & (1) & (2) & (3) & (4) & $(5)$ & (6) \\
\hline & Session & $\underline{\mathrm{P}-\mathrm{P}_{\mathrm{c}}}$ & Identical & Market & Market & $\rho_{\text {costs losing }}$ \\
\hline & & & $\underline{\text { Prices }}^{\mathrm{a}}$ & Sharing & Rotation $^{\mathrm{c}}$ & $\begin{array}{l}\mu_{\text {costs, losing }} \\
\text { postings }\end{array}$ \\
\hline & & Set C & ost Marke & & & \\
\hline & $n-s-f r 1$ & -3.3 & 1 & 4 & 0 & \\
\hline No & $n-s-f r 2$ & 0.6 & 0 & 2 & 0 & \\
\hline Commun- & $n-s-r f 1$ & -2.3 & 1 & 3 & 0 & \\
\hline ications & $n-s-r f 2$ & 9.1 & 1 & 4 & 0 & \\
\hline & $c-s-d i 1$ & 52.0 & 9 & 8 & 0 & \\
\hline Commun- & $c-s-d i 2$ & 63.2 & 6 & 6 & 0 & \\
\hline ications & $c-s-i d 1$ & 65.0 & 10 & 10 & 0 & \\
\hline & $c-s-i d 2$ & 5.0 & 10 & 10 & 0 & \\
\hline & & dogeno & us Cost M & arkets & & \\
\hline & $n-e-f r l$ & 14.4 & 0 & 0 & 9 & 0.46 \\
\hline No & $n-e-f r 2$ & 7.5 & 0 & 0 & 0 & 0.44 \\
\hline Commun- & $n-e-r f 1$ & -2.3 & 0 & 0 & 10 & 0.68 \\
\hline ications & $n-e-r f 2$ & 10.5 & 0 & 0 & 0 & 0.20 \\
\hline & $c-e-d i l$ & 64.0 & 0 & 0 & 9 & $0.00^{\mathrm{e}}(.69)$ \\
\hline Commun- & $c-e-d i 2$ & 67.8 & 0 & 0 & 10 & 0.26 \\
\hline ications & $c-e-i d 1$ & 43.3 & 0 & 3 & 0 & $0.14\left(.98^{f}\right)$ \\
\hline & $c-e-i d 2$ & 65.0 & 0 & 0 & 10 & 0.00 \\
\hline Jumber of se & niformly $\mathrm{p}$ & the san & e price in a & period & & \\
\hline Number of ti & seller each & the same & quantity in & a period. & & \\
\hline $\begin{array}{l}\text { Number of tir } \\
\text { djacent perioc }\end{array}$ & $\begin{array}{l}\text { vhen a sing } \\
\text { r rotations }\end{array}$ & $\begin{array}{l}\text { ler make } \\
\text { er than tw }\end{array}$ & $\begin{array}{l}\text { all sales in } \\
\mathrm{o} \text {, quantities }\end{array}$ & $\begin{array}{l}\text { period, and } \\
\text { must rotation }\end{array}$ & $\begin{array}{l}\text { when anothe } \\
\mathrm{n} \text { among sell }\end{array}$ & $\begin{array}{l}\text { er seller sells all units in an } \\
\text { lers in sequence. }\end{array}$ \\
\hline $\begin{array}{l}\text { In calculating } \\
\text { offered. Where } \\
\text { outliers are tru }\end{array}$ & $\begin{array}{l}\text { se correlatio } \\
\text { ts are hetero } \\
\text { d at } r+80\end{array}$ & $\begin{array}{l}\text { ach posti } \\
\text { ous, the }\end{array}$ & $\begin{array}{l}\text { ng is weighte } \\
\text { average cost }\end{array}$ & $\begin{array}{l}\text { d equally, in } \\
\text { of offered un }\end{array}$ & $\begin{array}{l}\text { idependent o } \\
\text { its is used as }\end{array}$ & $\begin{array}{l}\text { f the number of units } \\
\text { the relevant cost. The }\end{array}$ \\
\hline Excludes fina & iod, where & ection oc & curred. Paren & thetical num & ber includes & final period. \\
\hline $\begin{array}{l}\text { Excludes per } \\
\text { ostings. }\end{array}$ & 1 and 32, & 年 & were not con & spiring. NB & (D) ता & lation is based on only 3 \\
\hline
\end{tabular}




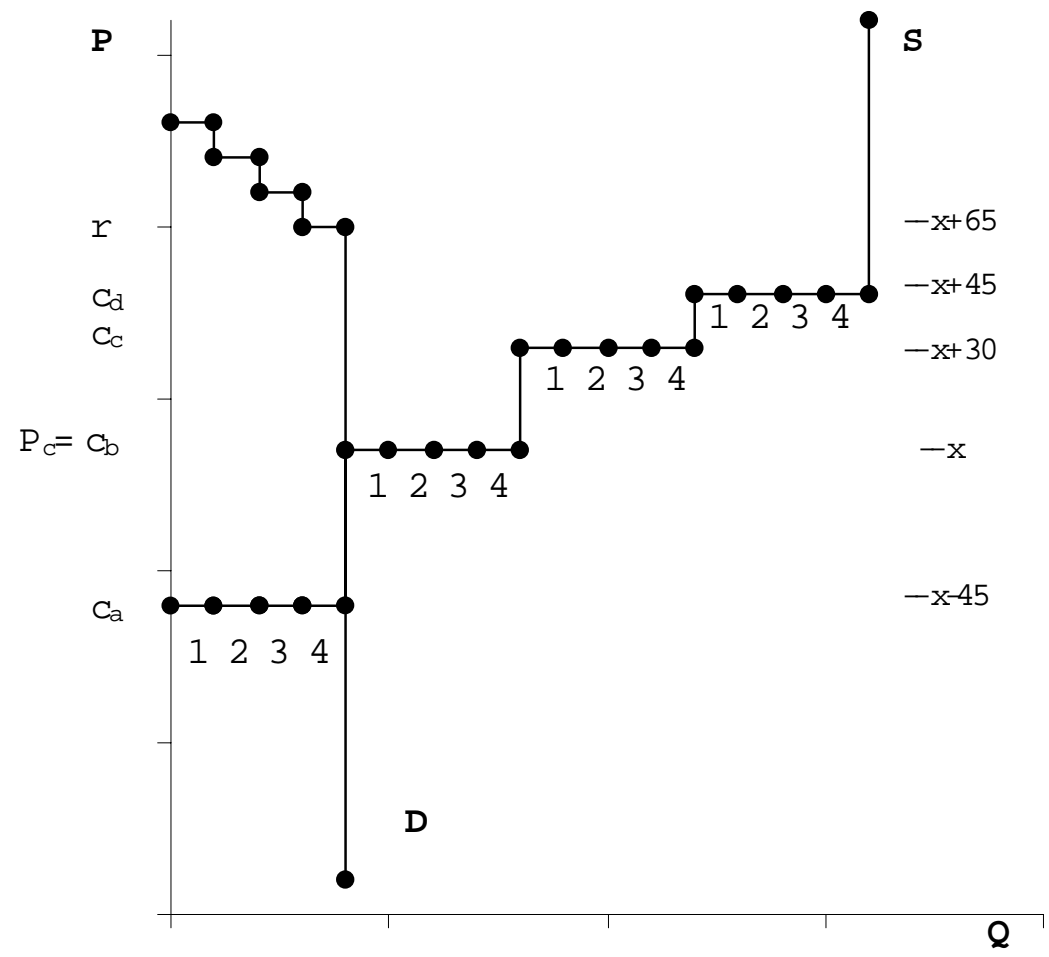

Figure 1. Supply and Demand Arrays for the Set Cost Design. Key: Unit costs for each of the four sellers S1 to S4 are indicated by the numbers 1 to 4 printed below the cost curve. 


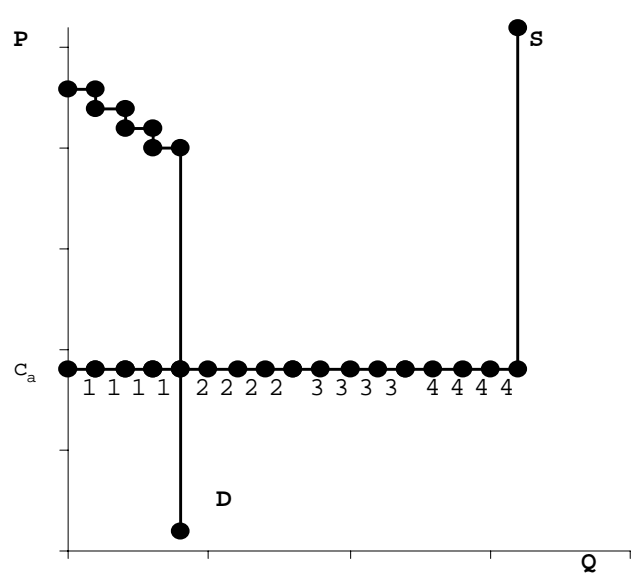

Period 1

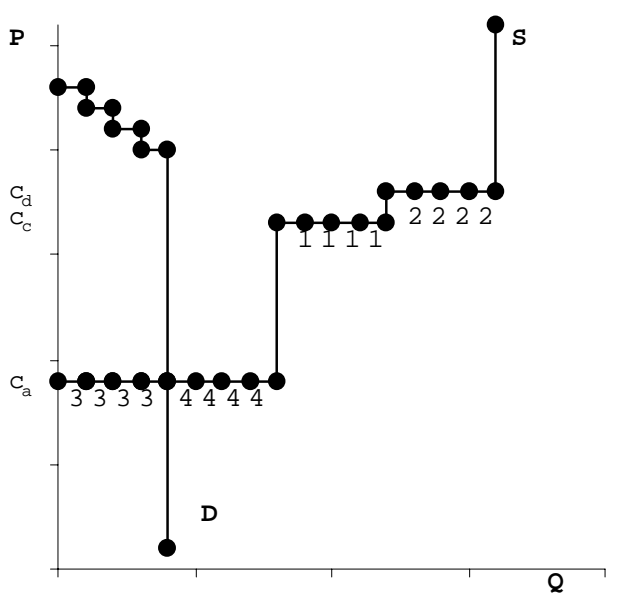

Period 3

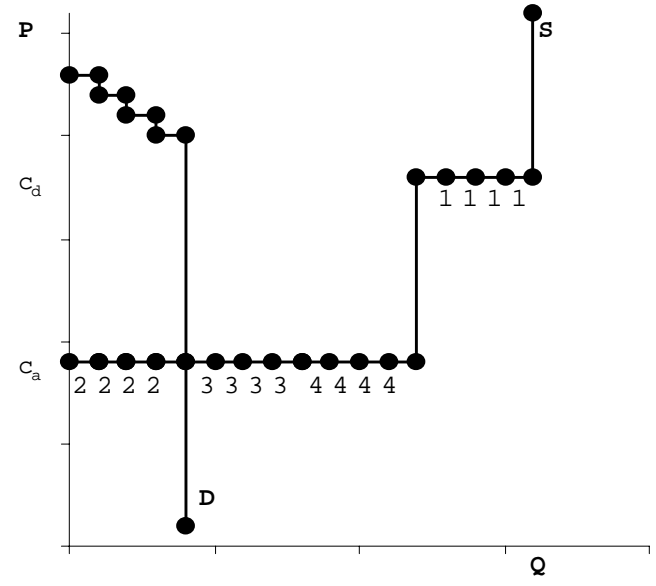

Period 2

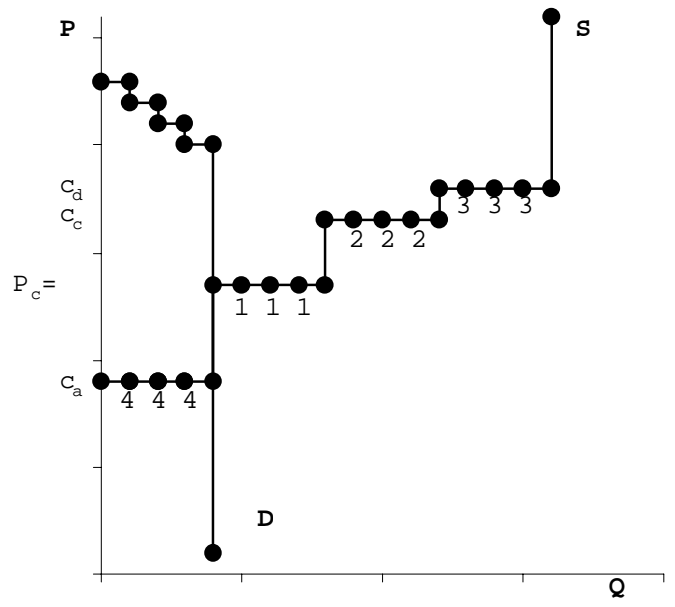

Period 4

Figure 2. Supply and Demand Arrays for the Endogenous Cost Design. Key: numbers printed below the cost curves indicate unit costs for sellers S1 to S4. After winning an auction in one period (e.g., S1 in period 1), the firm operates at capacity, and could only take on another project at the high marginal $\operatorname{cost} \mathrm{c}_{\mathrm{d}}$. In subsequent periods the constraint becomes less binding as resources are freed up from the original project. 


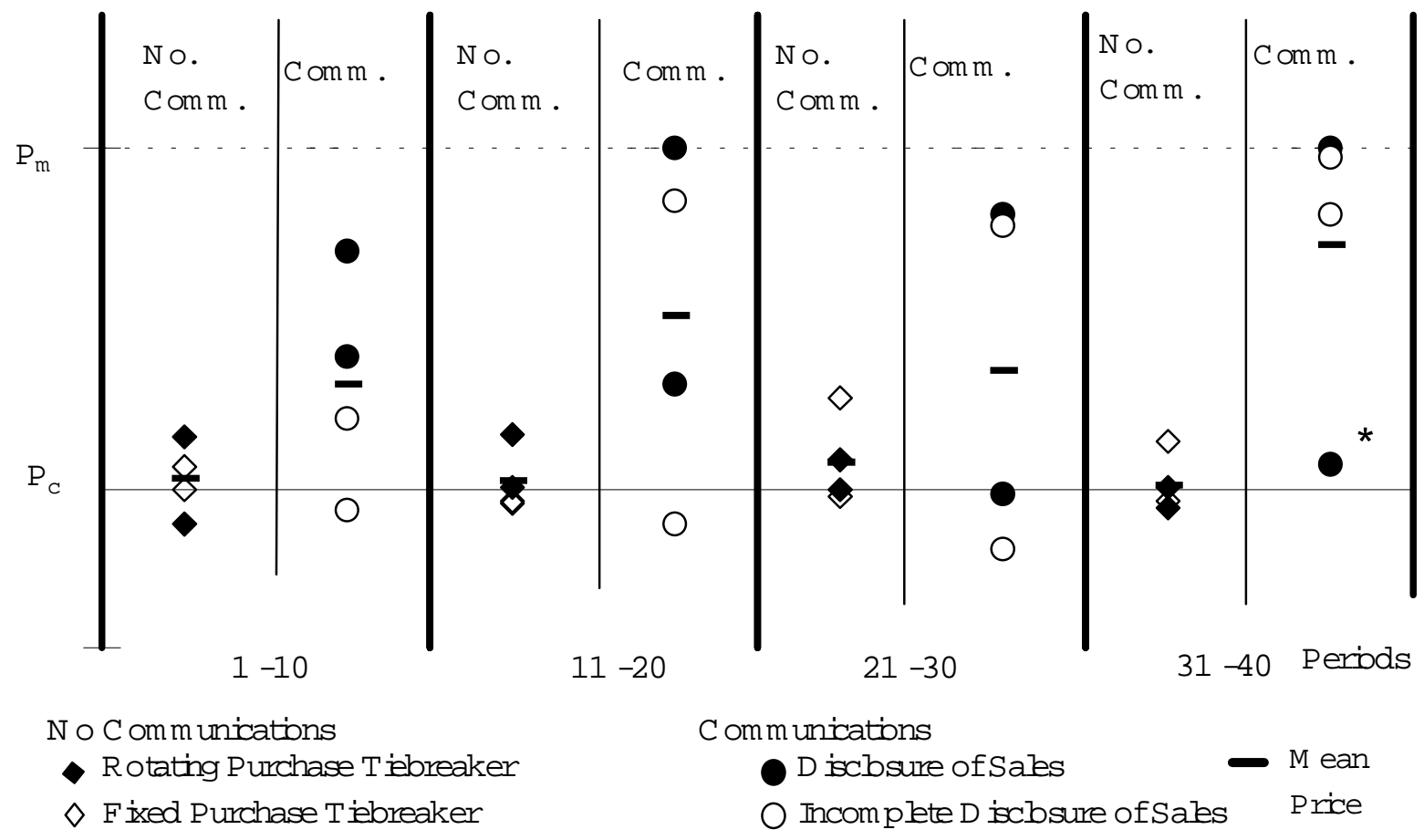

Figure 3. Mean Contract Prices in 10 Period Intervals for the Set Cost Sessions.

Endogenous C ost M arkets

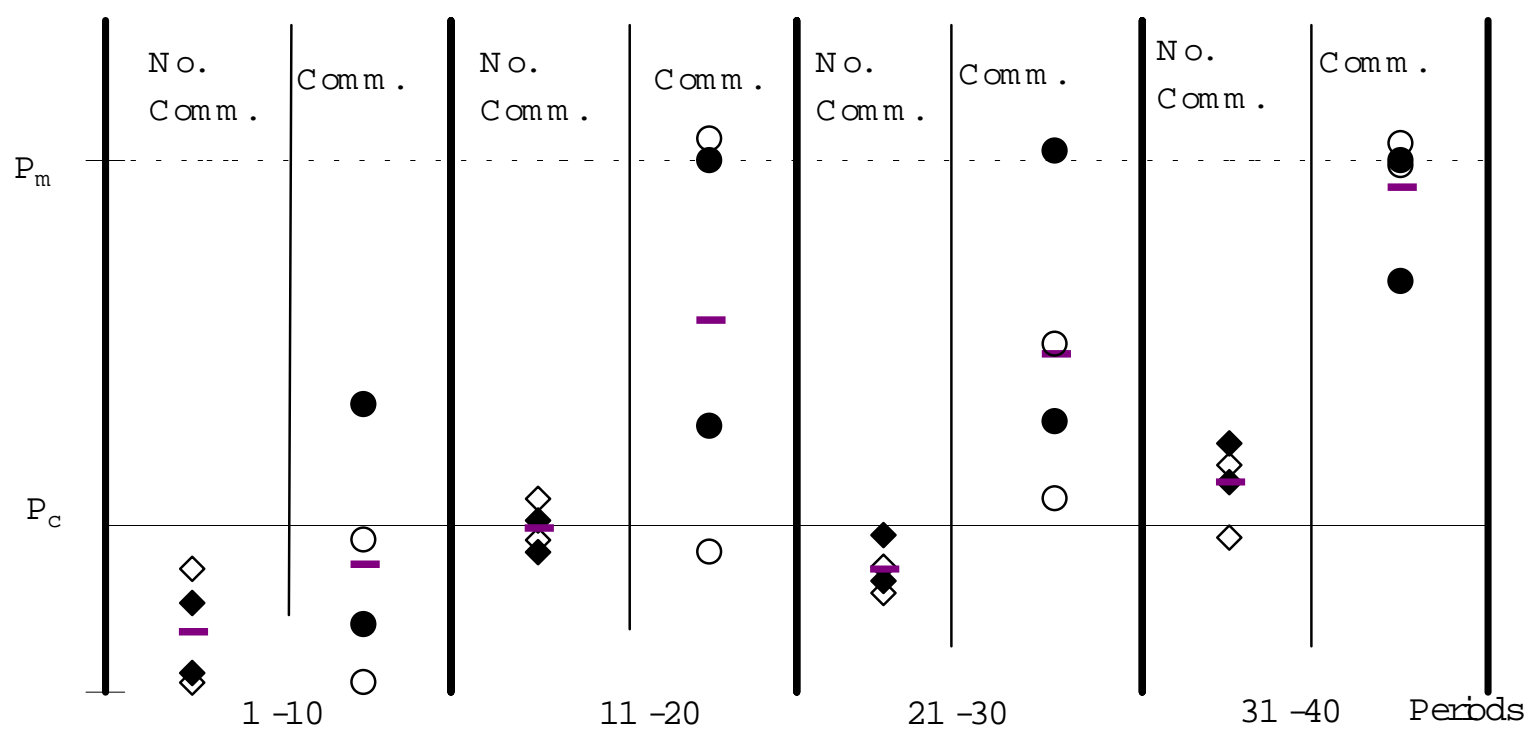

$\mathrm{N} \circ \mathrm{C}$ om m unications

$\checkmark$ Rotating Purchase T iebreaker

C omm unications

$\diamond \mathrm{F}$ ixed P urchase T iebreaker

D iscbsure ofSales $\quad$ M ean
P rice

Figure 4. Mean Contract Prices in 10 Period Intervals for the Endogenous Cost Sessions. 


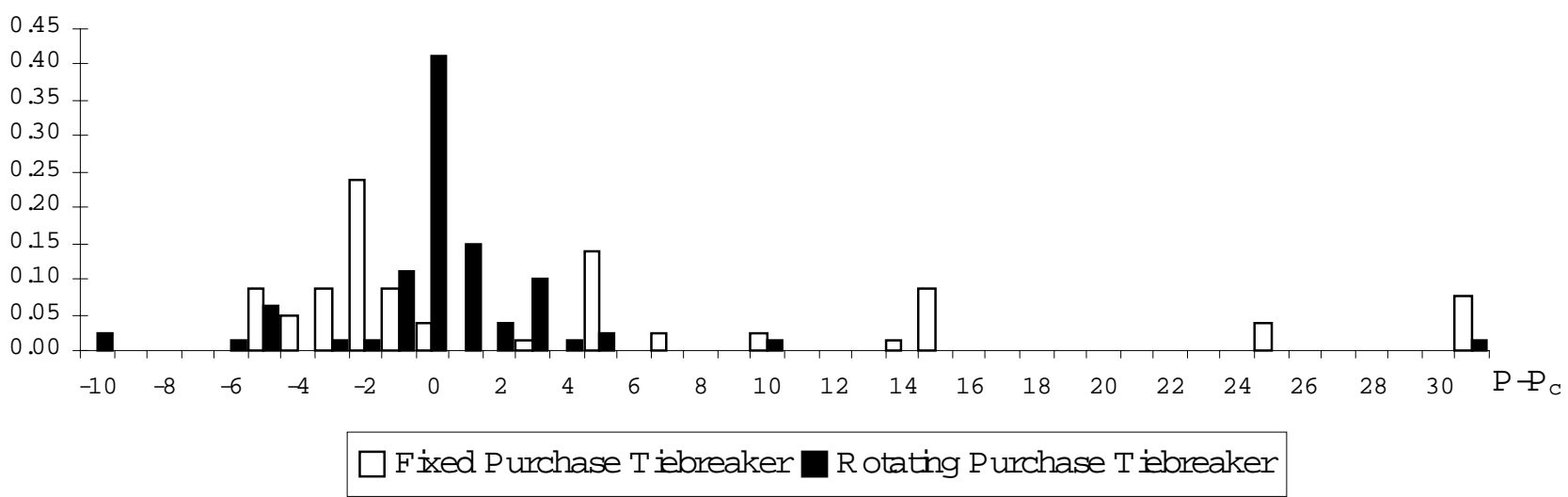

Figure 5. The distribution of price posting deviations from $P_{c}$ in periods $31-40$ of session in the set cost design, without communication. 
